\title{
Editorial \\ Enological Repercussions of Non-Saccharomyces Species in Wine Biotechnology
}

\author{
Antonio Morata \\ Department of Chemistry and Food Technology, Universidad Politécnica de Madrid (UPM), 28040 Madrid, \\ Spain; antonio.morata@upm.es
}

Received: 30 July 2019; Accepted: 1 August 2019; Published: 5 August 2019

The use of non-Saccharomyces yeasts in enology has increased since the beginning of the current century because of the potential improvements they can produce in wine sensory quality. Several review articles have described the potential of some non-Saccharomyces species [1-3] and the suitable criteria to select them $[4,5]$ according to the effects of the species on wine color, aroma, body or structure. Most non-Saccharomyces species have low fermentative power, which makes it necessary to use them in sequential fermentations with $S$. cerevisiae to completely deplete the sugars. Moreover, some of them have slow fermentation kinetics, which is a drawback for a competitive implantation in must containing S. cerevisiae indigenous populations. Emerging technologies to control wild indigenous yeasts can facilitate the development, growth and fermentative activity of the inoculated non-Saccharomyces yeasts and, therefore, the suitable expression of their metabolic properties [6]. This special issue is focused on the description and review of several non-Saccharomyces species with great potential in wine biotechnology, some of which are frequently used at the winery scale, but also produced industrially as dried yeast or liquid inoculant [7].

Wine acidity, especially the $\mathrm{pH}$, is a key parameter in wine that controls microbial development and chemical stability. Traditional $\mathrm{pH}$ control is driven by acidification processes with tartaric acid or modern ion exchanger techniques, which unfortunately affect sensory quality. The biological modulation of wine acidity can be done efficiently by several non-Saccharomyces species, by the production of lactic acid by Lachancea thermotolerans or succinic acid by Candida stellata, the demalication by Schizosaccharomyces pombe or Pichia kudriavzevii, and the control of volatile acidity in sequential fermentations with Torulaspora delbrueckii or Zygosaccharomyces florentinus highlight the possibilities of non-Saccharomyces in the improvement of wine acidity [8].

Biological acidification by L. thermotolerans is a powerful tool to control $\mathrm{pH}$ in warm areas [9]. The production of acidity is performed from sugars and the product lactic acid is a stable metabolite during winemaking but also through stabilization and aging. The formation of several metabolites with sensory repercussions has also been described in this species. Acidification by L. thermotolerans is a natural biotechnology that helps to keep lower and more effective levels of molecular and free $\mathrm{SO}_{2}$. Currently, in our laboratory we have selected strains of this species able to ferment at more than $12 \%$ potential alcohol, which opens the door to single fermentations with single inoculums of L. thermotolerans.

Wine deacidification by metabolization of malic acid is an essential step in red winemaking. This acid is unstable during stabilization and aging, and can produce microbial hazes if not eliminated previously. Usually, malic acid is transformed into lactic acid by malolactic fermentation produced by lactic acid bacteria, mainly Oenococcus oeni, due to the specific composition of wine. Alternatively, S. pombe is able to metabolize malic acid by the maloalcoholic fermentation pathway. The advantages are the fast and efficient degradation of malic acid and at the same time $S$. pombe can produce the alcoholic fermentation. Moreover, its use reduces the formation of biogenic amines. Also, the peculiar metabolism of $S$. pombe facilitates the formation of vitisin A pyranoanthocyanin pigments, with positive effects on color stability [10]. 
Among the pioneer species used in enology is T. delbrueckii, with medium fermentative power, some strains reach $9 \%-10 \%$ in alcohol with a high fermentation purity. The production of acetic esters and other specific aromas makes this yeast a key option to improve wine aroma, but it also has interesting effects on the body and structure [11]. Recently, it has been used in sparkling wines to make more complex base wines, whilst also increasing the structure during bottle aging [12].

The production of acetic esters is an interesting strategy to improve a wine's aromatic profile. The use of Wickerhamomyces anomalus helps to increase the contents of several esters, specifically 2-phenyl-ethyl acetate, with positive floral profiles [13]. The main drawback of this species is the high production of acetic acid, which can be partially controlled with suitable strain selection, but also through its use in sequential fermentation with S. cerevisiae. Apiculate species, such as the Hanseniaspora/Kloeckera genera, are also described as strong producers of acetate esters, and many species enhance the formation of 2-phenyl-ethyl acetate; some also produce benzenoids or nor-isoprenoids. Moreover, they tend to have an interesting effect on structure by producing full bodied wines [14]. Some of these species, as well as Metschnikowia pulcherrima and C. stellata, are able to release extracellular hydrolytic enzymes, such as $\beta$-glucosidases or c-lyases, that help improve the varietal aroma by releasing free terpenes or thiols $[15,16]$. A wide pool of enzymatic activities can also be found in saprophytic Aureobasidium pullulans, several of these enzymes can be purified with useful applications in enology [17]. A. pullulans is a typical yeast-fungus that can be found in the indigenous microbiota of the berry together with the apiculate genera Hanseniaspora/Kloeckera.

Spoilage yeasts such as Zygosaccharomyces rouxii, Saccharomycodes ludwigii or Brettanomyces bruxellensis may be difficult to handle at specific winemaking stages. Usually, the main concern of the enologist is their control and elimination from musts and wines, but also the analysis of their populations and their main marker metabolites. However, these non-Saccharomyces species sometimes have interesting applications in fermentative industries. Zygosaccharomyces rouxii is a frequent osmophilic spoilage species that causes re-fermentations in sweet wines and other drinks, such as fruit juices and soft beverages. Its control can be done using additives as DMDC, emerging antimicrobials as LfcinB, or cold pasteurization processes as DBD, US, UHPH or PEFs [18]. Saccharomycodes ludwigii is a strong fermenting yeast able to completely finish grape sugars; it also shows a strong resistance to high $\mathrm{SO}_{2}$ levels. Some interesting applications are now being described, such as the use of this species in the reduction of the alcoholic degree of beers or in the production of ciders. In enology, the production of off-flavors reduces a lot the potential use of $S$. ludwigii in wine fermentation. The control measures used to reduce its prevalence in wines are the use of emerging physical technologies, chemical additives such as DMDC, but also natural products such as chitosan or biological control with killer yeasts [19]. The use of biological control with yeasts able to produce antimicrobial peptides is a novelty in the elimination of Brettanomyces spp. [20]. This spoilage yeast degrades the sensory quality of the wine as it develops during barrel aging, usually affecting more expensive wines by producing several unpleasant molecules [21]. Conventional control is based on the use of $\mathrm{SO}_{2}$ and hygiene measures, however both parameters are difficult to control and maintain during long periods in difficult materials such as barrel wood. The use of $C$. intermedia as a selective bio-controller is a natural way to reduce the damages produced by Brettanomyces. Bio-protection and biological management of spoilage and undesired yeast can be also done by using $M$. pulcherrima, the production of the pigment pulcherrimin and their effect on iron chelation helps to eliminate competitive yeasts in grapes or at the beginning of fermentation [15].

If the twentieth century saw the explosion of S. cerevisiae applications, non-Saccharomyces yeasts open up a world of new biotechnologies in the twenty-first century, including improved fermentations, with more complex and differentiated sensory profiles in wines, bioprotection applications, enzymatic activities, acidity modulation, improvement of aging processes, reduction of toxic molecules and additives, and many other possibilities to discover. Some of these potentials contribute to the adaptation of wine to regions and terroirs, even to the ecological changes produced by global warming.

Funding: This research received no external funding. 
Conflicts of Interest: The authors declare no conflict of interest.

\section{References}

1. Ciani, M.; Maccarelli, F. Oenological properties of non-Saccharomyces yeasts associated with wine-making. World J. Microbiol. Biotechnol. 1997, 14, 199-203. [CrossRef]

2. Jolly, N.P.; Augustyn, O.P.H.; Pretorius, I.S. The role and use of non-Saccharomyces yeasts in wine production. South Afr. J. Enol. Vitic. 2006, 27, 15-39. [CrossRef]

3. Jolly, N.P.; Varela, C.; Pretorius, I.S. Not your ordinary yeast: Non-Saccharomyces yeasts in wine production uncovered. FEMS Yeast Res. 2014, 14, 215-237. [CrossRef] [PubMed]

4. Comitini, F.; Gobbi, M.; Domizio, P.; Romani, C.; Lencioni, L.; Mannazzu, I.; Ciani, M. Selected non-Saccharomyces wine yeasts in controlled multistarter fermentations with Saccharomyces cerevisiae. Food Microbiol. 2011, 28, 873-882. [CrossRef] [PubMed]

5. Suárez-Lepe, J.A.; Morata, A. New trends in yeast selection for winemaking. Trends Food Sci. Technol. 2012, 23, 39-50. [CrossRef]

6. Morata, A.; Loira, I.; Vejarano, R.; González, C.; Callejo, M.J.; Suárez-Lepe, J.A. Emerging preservation technologies in grapes for winemaking. Trends Food Sci. Technol. 2017, 67, 36-43. [CrossRef]

7. Morata, A.; Suárez Lepe, J.A. New biotechnologies for wine fermentation and ageing. In Advances in Food Biotechnology; Ravishankar Rai, P.V., Ed.; John Wiley \& Sons, Ltd.: West Sussex, UK, 2016; pp. $293-295$.

8. Vilela, A. Use of Non-conventional Yeasts for Modulating Wine Acidity. Fermentation 2019, 5, 27. [CrossRef]

9. Morata, A.; Loira, I.; Tesfaye, W.; Bañuelos, M.A.; González, C.; Suárez Lepe, J.A. Lachancea thermotolerans Applications in Wine Technology. Fermentation 2018, 4, 53. [CrossRef]

10. Loira, I.; Morata, A.; Palomero, F.; González, C.; Suárez-Lepe, J.A. Schizosaccharomyces pombe: A Promising Biotechnology for Modulating Wine Composition. Fermentation 2018, 4, 70. [CrossRef]

11. Ramírez, M.; Velázquez, R. The Yeast Torulaspora delbrueckii: An Interesting But Difficult-To-Use Tool for Winemaking. Fermentation 2018, 4, 94. [CrossRef]

12. Ivit, N.N.; Kemp, B. The Impact of Non-Saccharomyces Yeast on Traditional Method Sparkling Wine. Fermentation 2018, 4, 73. [CrossRef]

13. Padilla, B.; Gil, J.V.; Manzanares, P. Challenges of the Non-Conventional Yeast Wickerhamomyces anomalus in Winemaking. Fermentation 2018, 4, 68. [CrossRef]

14. Martin, V.; Valera, M.J.; Medina, K.; Boido, E.; Carrau, F. Oenological Impact of the Hanseniaspora/Kloeckera Yeast Genus on Wines-A Review. Fermentation 2018, 4, 76. [CrossRef]

15. Morata, A.; Loira, I.; Escott, C.; del Fresno, J.M.; Bañuelos, M.A.; Suárez-Lepe, J.A. Applications of Metschnikowia pulcherrima in Wine Biotechnology. Fermentation 2019, 5, 63. [CrossRef]

16. García, M.; Esteve-Zarzoso, B.; Cabellos, J.M.; Arroyo, T. Advances in the Study of Candida stellata. Fermentation 2018, 4, 74. [CrossRef]

17. Bozoudi, D.; Tsaltas, D. The Multiple and Versatile Roles of Aureobasidium pullulans in the Vitivinicultural Sector. Fermentation 2018, 4, 85. [CrossRef]

18. Escott, C.; Del Fresno, J.M.; Loira, I.; Morata, A.; Suárez-Lepe, J.A. Zygosaccharomyces rouxii: Control Strategies and Applications in Food and Winemaking. Fermentation 2018, 4, 69. [CrossRef]

19. Vejarano, R. Saccharomycodes ludwigii, Control and Potential Uses in Winemaking Processes. Fermentation 2018, 4, 71. [CrossRef]

20. Peña, R.; Chávez, R.; Rodríguez, A.; Ganga, M.A. A Control Alternative for the Hidden Enemy in the Wine Cellar. Fermentation 2019, 5, 25. [CrossRef]

21. Suárez, R.; Suárez-Lepe, J.A.; Morata, A.; Calderón, F. The production of ethylphenols in wine by yeasts of the genera Brettanomyces and Dekkera: A review. Food Chem. 2007, 102, 10-21. [CrossRef]

(C) 2019 by the author. Licensee MDPI, Basel, Switzerland. This article is an open access article distributed under the terms and conditions of the Creative Commons Attribution (CC BY) license (http://creativecommons.org/licenses/by/4.0/). 